\title{
Long-term stability in modelled zooplankton influx could uphold major fish spawning grounds on the Norwegian continental shelf
}

\author{
Anders Frugård Opdal and Frode B. Vikebø
}

\section{Supplementary figure set}

Here we present a supplementary figure set for three additional simulations, with reference to the figure set of the main article [Original, WUD Feb $4^{\text {th }}$ ]. The additional simulations have a uniform overwintering distribution as shown in figure $\mathrm{S} 1$ and are initiated with a fixed overwintering depth of $400 \mathrm{~m}$, a fixed dry weight of $50 \mu \mathrm{g} \mathrm{C}$, and three different wake-up days (WUD, start of simulation). Feb $4^{\text {th }}$ [Uniform, WUD Feb $4^{\text {th }}$ ], Jan $20^{\text {th }}$ [Uniform, WUD Jan $20^{\text {th }}$ ] and Feb $20^{\text {th }}$ [Uniform, WUD Feb $20^{\text {th }}$. In all simulations, individuals follow the same growth and behavioural patterns as described in the Materials and methods section.

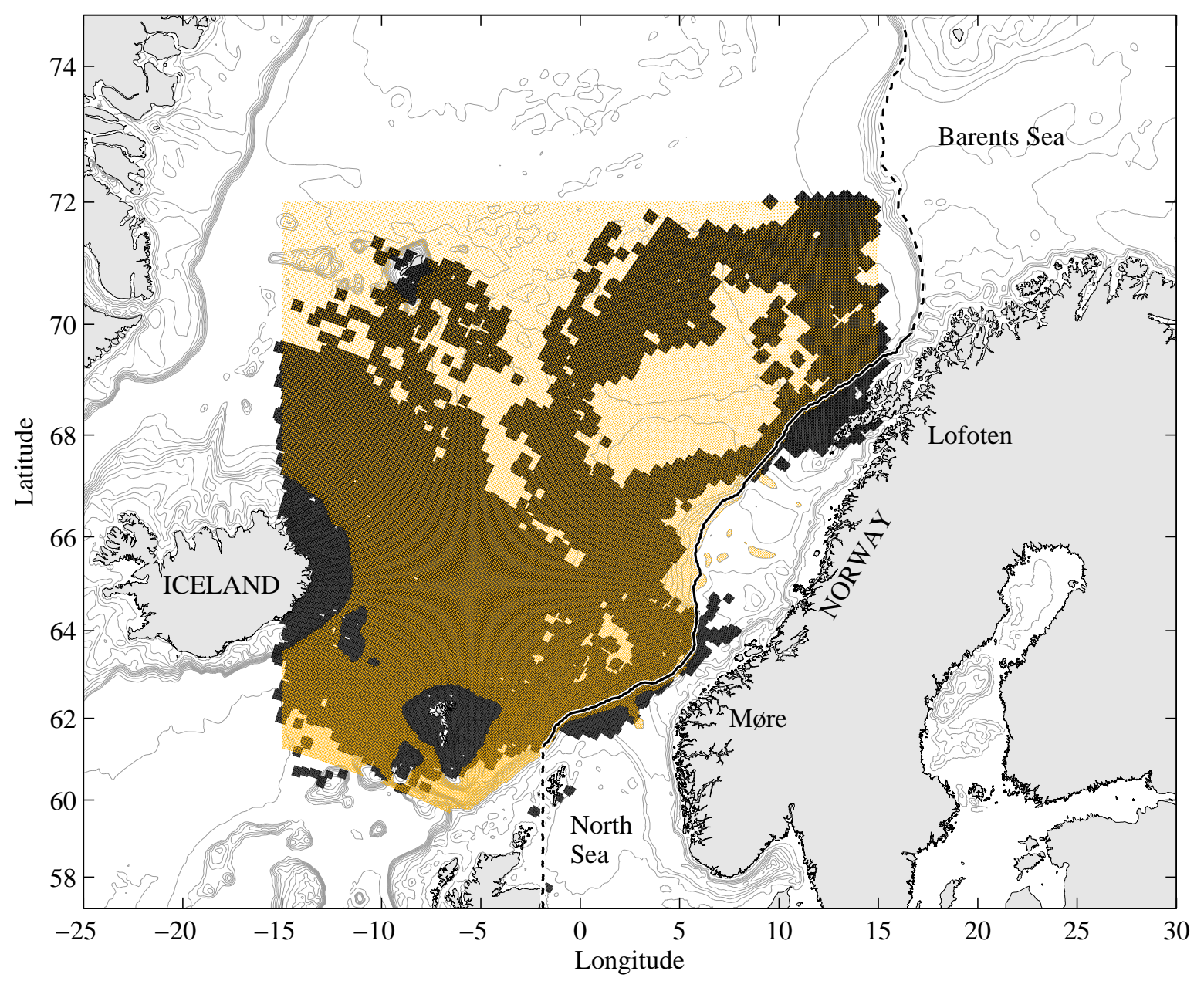

Figure S1. Horizontal coverage of the uniform overwintering distribution of ca 70.000 particles in the Norwegian Sea (yellow). Silhouette of the evolved overwintering distribution from Hjøllo et al. (2012) can been seen in black. Defined borders to the North Sea (southern dashed line), the Norwegian continental shelf break (whole line) and the Barents Sea opening (northern dashed line) are denoted together with major spawning areas for Northeast Arctic cod (Lofoten) and Norwegian spring spawning herring (Møre). 
[Original, WUD Feb $4^{\text {th }}$ ]

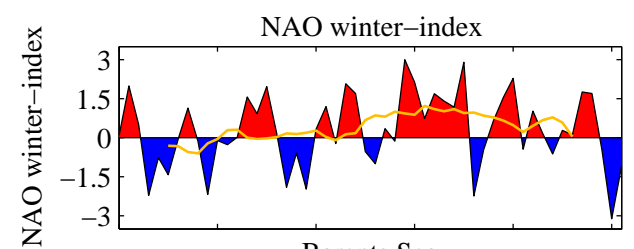

Barents Sea

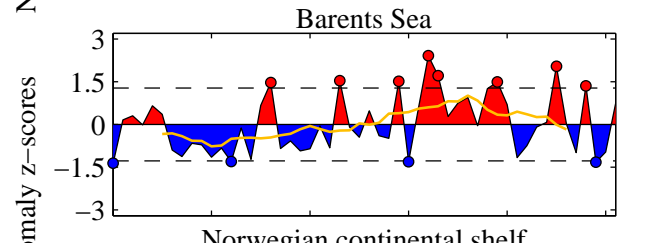

[Uniform, WUD Feb $4^{\text {th }}$ ]

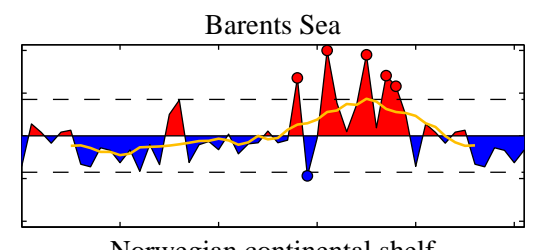

Norwegian continental shelf

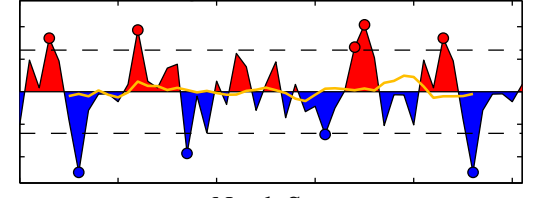

North Sea

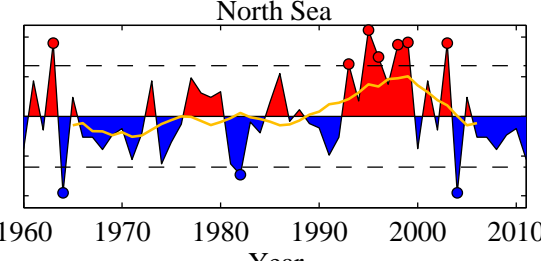

[Uniform, WUD Jan $20^{\text {th }}$ ]

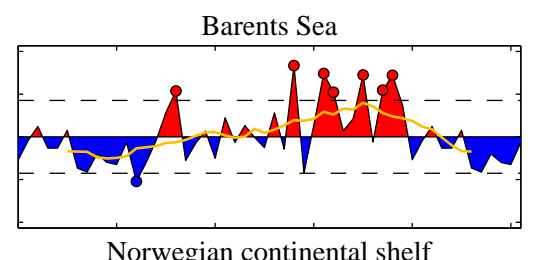

Norwegian continental shelf
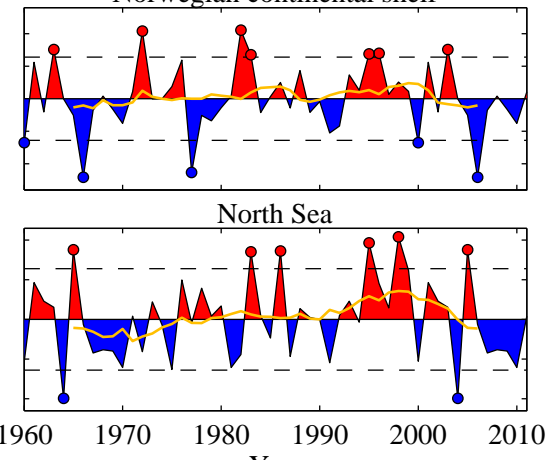

[Uniform, WUD Feb $20^{\text {th }}$ ]

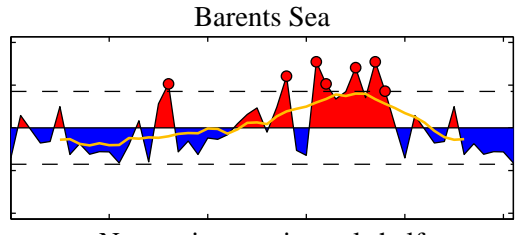

Norwegian continental shelf

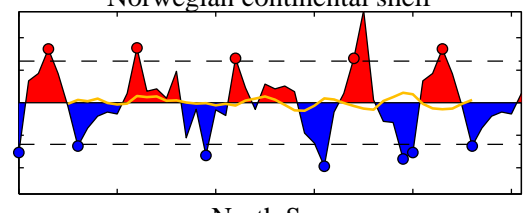

North Sea

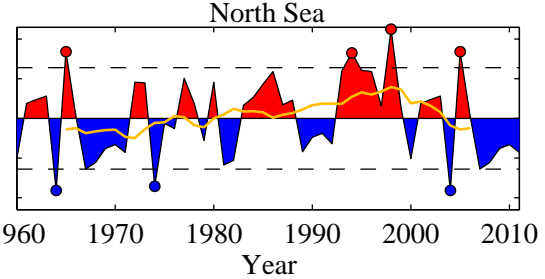

Figure S2. The NAO winter-index (top panel left panel), and the inter-annual variation (from 4 simulations) in total cross-shelf transport of calanus quantified by yearly anomaly z-scores 100 days after wake up day for the Barents Sea opening, the Norwegian shelf break and the North Sea cut-off border. Yellow line denote the 10 year simple moving average $(\mathrm{n}=42)$, and dashed lines are the upper and lower limits of the $80 \%$ confidence intervals (CI). Years with extreme high or low anomalies (outside the $80 \% \mathrm{CI}$ ) are indicated with a red or blue coloured dot, respectively. 
[Original, WUD Feb $4^{\text {th }}$ ]
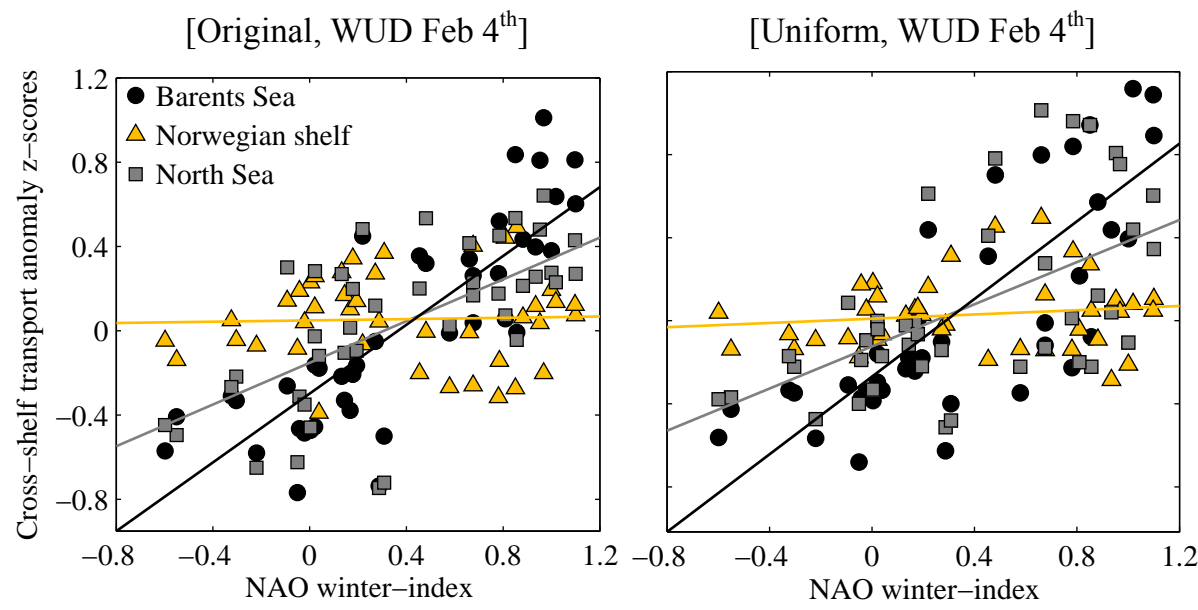

[Uniform, WUD Jan $20^{\text {th }}$ ]

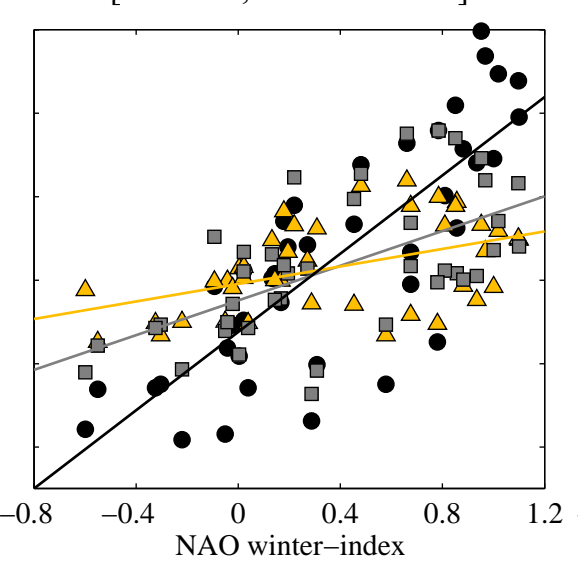

[Uniform, WUD Feb $20^{\text {th }}$ ]

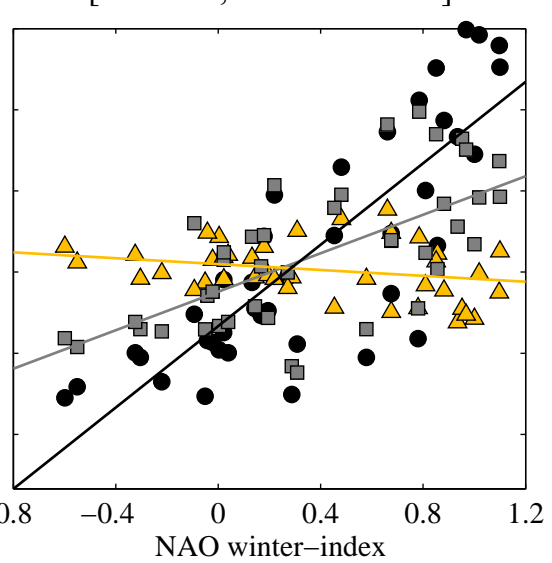

\begin{tabular}{|l|l|l|l|l|}
\hline Simulation/Area & Original, WUD Feb 4 & Uniform, WUD Feb 4 & Uniform, WUD Jan 20 $^{\text {th }}$ & Uniform, WUD Feb 20 $^{\text {th }}$ \\
\hline Barents Sea & $R=0.83, p<0.001$ & $R=0.79, p<0.001$ & $R=0.82, p<0.001$ & $R=0.83, p<0.001$ \\
\hline Norwegian shelf & $R$ not significant & $R$ not significant & $R=0.47, p=0.002$ & $R$ not significant \\
\hline North Sea & $R=0.65, p<0.001$ & $R=0.57, p<0.001$ & $R=0.61, p<0.001$ & $R=0.66, p<0.001$ \\
\hline
\end{tabular}

Figure S3. Regression plots and lines between the 10 year moving average $(n=42)$ of the NAO winter index and calanus cross shelf-transport anomaly z-scores for the Barents Sea, the Norwegian continental shelf and the North Sea. Results of regression analysis for the four different simulations shown in table. 

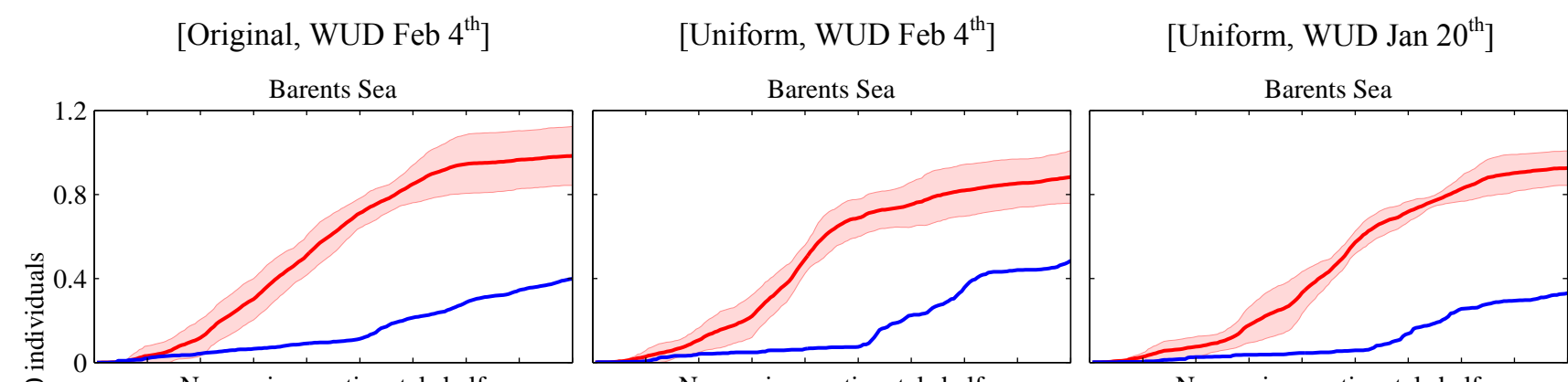

\section{[Uniform, WUD Feb $20^{\text {th }}$ ]}
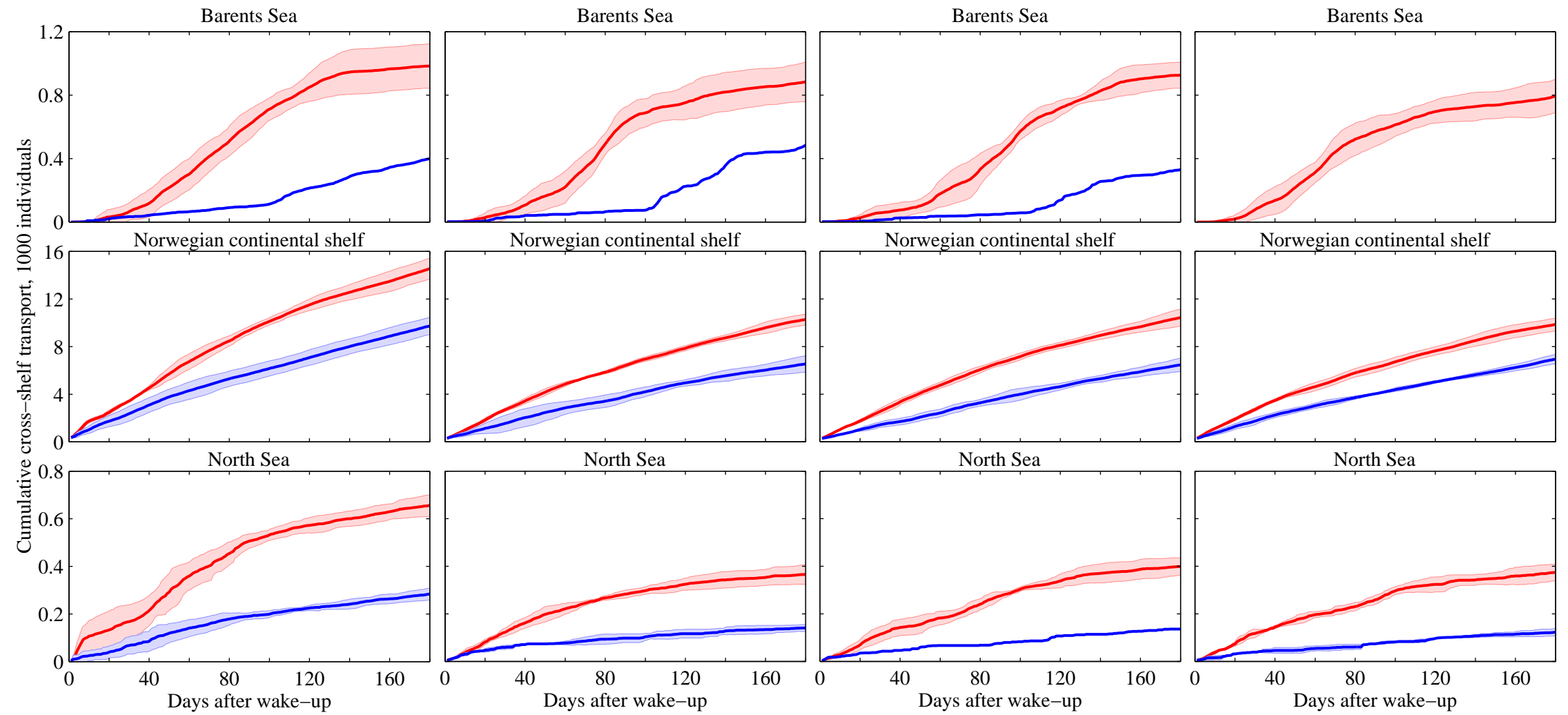

Figure S4. Average number of calanus transported over time through the Barents Sea opening (top panel), over the Norwegian continental shelf break (centre panel), and across the North Sea cut-off border (bottom panel) in years with high (red lines) and low (blue lines) cross-shelf transport anomaly z-scores (see figure S2). Shaded areas denote standard deviation. 

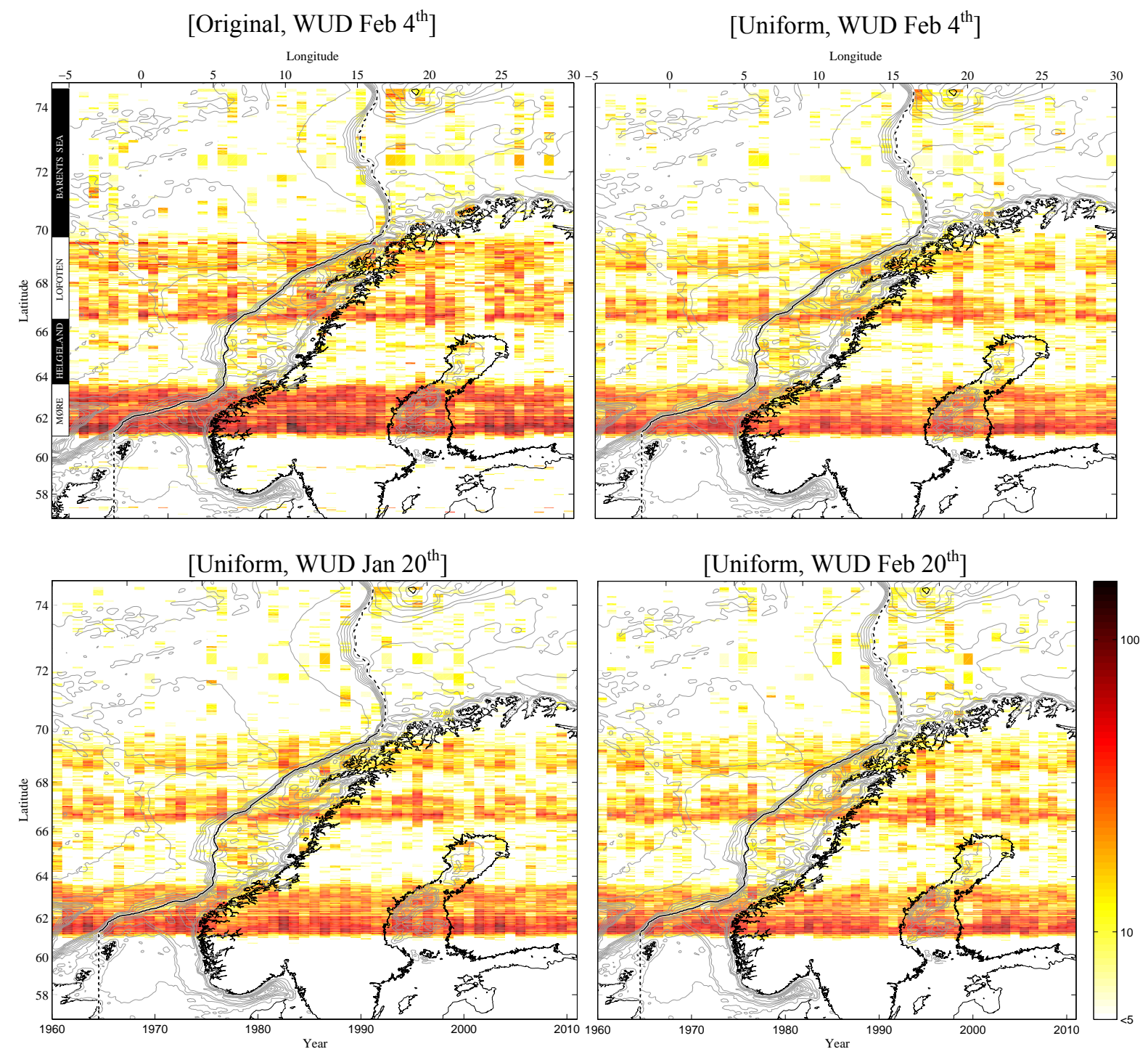

Figure S5. Location and abundance (colour scale, abundance) of particles transported across the eastern shelf boundaries after 100 days for all years (bottom axis). Superimposed (top axis) is depth contours (gray), coastlines (black), and the assigned border to the North Sea (southern dashed line) the continental shelf (whole line) and Barents Sea (northern dashed line). Areas with contrasting patterns in cross-shelf transport are marked with black and white bars with geographical names (Møre, Helgeland, Lofoten-Vesterålen and the Barents Sea). 


\section{[Original, WUD Feb $4^{\text {th }}$ ]}

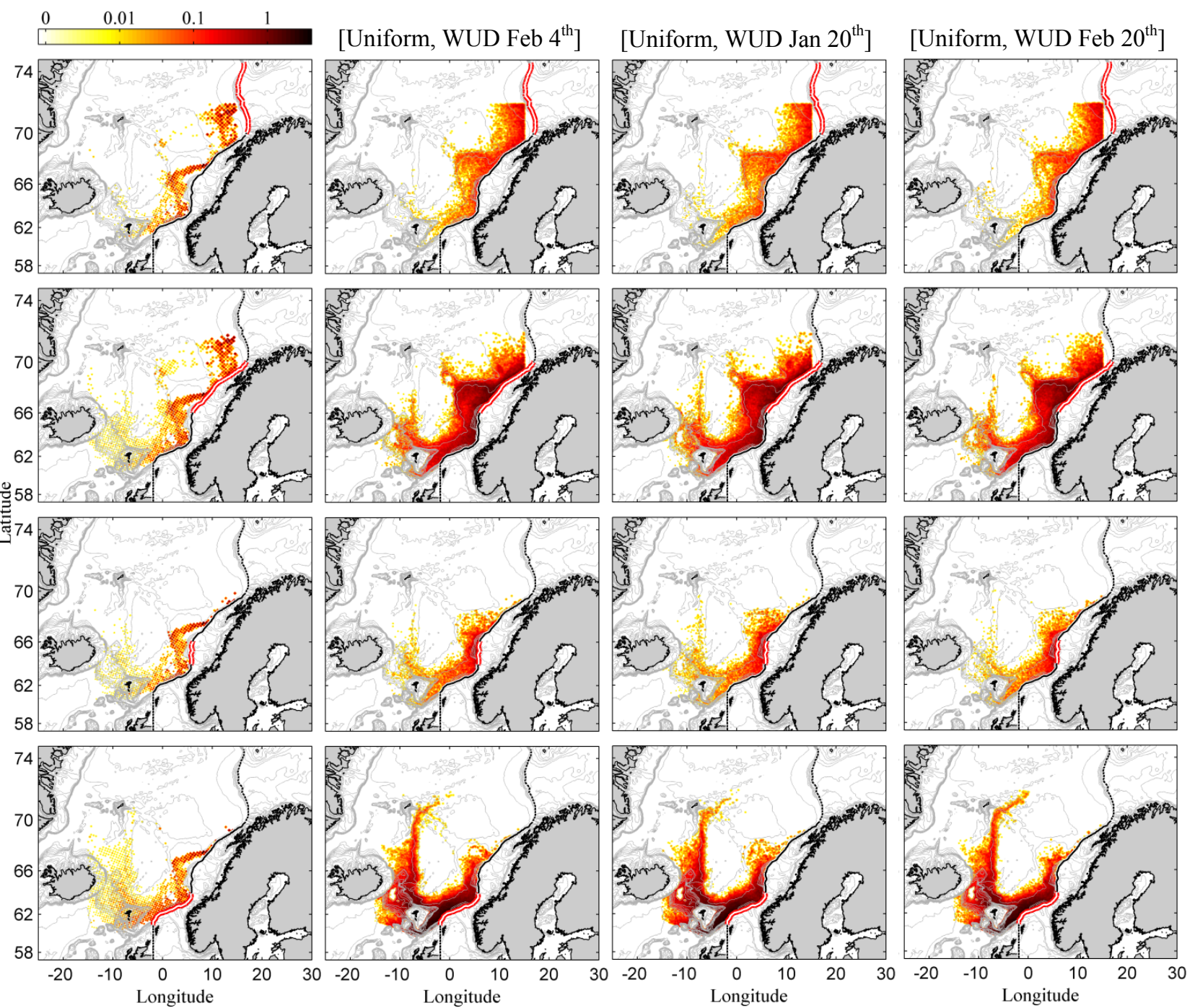

Figure S6. Integrated overwintering distribution ((colour scale, abundance)) for all years for calanus that are transported from the Norwegian Sea and across the different shelf boundary areas (denoted with double red line). The shelf boundary areas are selected based on the latitudinal variation in modelled cross-shelf transport shown in figure 6 , and indicate the Barents Sea $\left(1^{\text {st }}\right.$ row), the Lofoten-Vesterålen area ( $2^{\text {nd }}$ row $)$, and Helgeland area ( $3^{\text {rd }}$ row) and the Møre area $\left(4^{\text {th }}\right.$ row).

\section{References}

Hjøllo, S.S., Huse, G., Skogen, M.D., and Melle, W. 2012. Modelling secondary production in the Norwegian Sea with a fully coupled physical/primary production/individual-based Calanus finmarchicus model system. Marine Biology Research 8(5-6): 508-526. 